\title{
1 HOW THE INITIAL LEVEL OF TRUST IN AUTOMATED DRIVING IMPACTS DRIVERS' \\ 2 BEHAVIOUR AND EARLY TRUST CONSTRUCTION
}

3

4 J. B. Manchon ${ }^{1,2}$, Mercedes Bueno ${ }^{1}$, and Jordan Navarro ${ }^{2}$

$5 \quad{ }^{1}$ VEDECOM Institute, Versailles, France

$6 \quad{ }^{2}$ Laboratoire d'Etude des Mécanismes Cognitifs (EA 3082), University Lyon 2, Bron, France

8 Correspondence address: J. B. Manchon, Institut VEDECOM, 23 bis Allée des

9 Marronniers, 78000 Versailles, France; e-mail: jb.manchon@vedecom.fr.

10

11 Word count: 4,853 


\section{AbStRACT}

13 Trust in Automation is known to influence human-automation interaction and user

14 behaviour. In the Automated Driving (AD) context, studies showed the impact of drivers'

15 Trust in Automated Driving (TiAD), and linked it with, e.g., difference in environment

16 monitoring or driver's behaviour. This study investigated the influence of driver's initial

17 level of TiAD on driver's behaviour and early trust construction during Highly Automated

18 Driving (HAD). Forty drivers participated in a driving simulator study. Based on a trust

19 questionnaire, participants were divided in two groups according to their initial level of

20 TiAD: high (Trustful) vs. low (Distrustful). Declared level of trust, gaze behaviour and Non-

21 Driving-Related Activities (NDRA) engagement were compared between the two groups

22 over time. Results showed that Trustful drivers engaged more in NDRA and spent less

23 time monitoring the road compared to Distrustful drivers. However, an increase in trust

24 was observed in both groups. These results suggest that initial level of TiAD impact

25 drivers' behaviour and further trust evolution.

27 Keywords: trust in automation, automated driving, driver's behaviour 


\section{INTRODUCTION}

29 Automated driving is currently becoming part of the traffic, and such technologies raise

30 new questions. As automation capabilities progress, driver-vehicle interaction and

31 cooperation evolve acutely (Navarro, 2019). For example, Highly Automated Driving

32 (HAD, level 4, SAE, 2016) provides full control of the driving task, allowing drivers to

33 entirely focus on Non-Driving-Related Activities (NDRA), as the vehicle can perform a

34 minimum risk manoeuvre if the driver is unable to resume manual control.

35 Trust is a key element influencing Human-Machine Interaction (HMI) in many ways (Lee

36 \& See, 2004; Parasuraman \& Riley, 1997), deeply impacting human-system overall

37 performance (Lee \& Moray, 1992), and being a determinant of automation use as well

38 (Parasuraman \& Riley, 1997; Schaefer et al., 2016). Trust in Automation (TiA) is

39 commonly defined as "the attitude that an agent will help achieve an individual's goals in

40 a situation characterized by uncertainty and vulnerability" (Lee \& See, 2004). It has been

41 widely studied during past decades with automation experts (e.g., plane pilots, power

42 plant supervisors, see Parasuraman \& Riley, 1997) as a major reliance factor (e.g., Lee

43 \& See, 2004; Sheridan, 2019), but the wide range of drivers' level of experience, abilities,

44 and expectations combined with the high variety of driving contexts open a relatively new

45 paradigm (Manchon et al., 2020). Trust in Automated Driving (TiAD) is defined here as

46 the attitude a driver has about HAD, that allows to delegate of the driving task to the

47 automation to improve safety and comfort, while the risk of accident exist.

48 TiA seems to be high when operators' self-confidence is low, but low in the opposite

49 situation (Lee \& Moray, 1994). Most car-users might be prone to misjudge their driving

50 skills leading to poor calibrated TiAD (Wintersberger \& Riener, 2016). Trust calibration 
51 describes the conformity of an operator's TiA with actual automation capabilities (Lee \&

52 See, 2004). When this calibration is not correct, two kind of situations may happen. Over-

53 trust could lead to hazardous conditions when using this kind of system in traffic (Hancock

54 et al., 2011; Hoff \& Bashir, 2015; Parasuraman \& Riley, 1997), as shown by the many

55 accidents due to poor ADASs monitoring (e.g., NHTSA, 2017). Distrust might be equally

56 dangerous in specific circumstances, for example if the driver maintained manual control

57 when experiencing drowsiness. It is therefore important to understand drivers' trust

58 calibration process to design well-accepted and safer automated driving systems that

59 inspire a proper level of trust (Helldin et al., 2013; Zhang et al., 2019).

60 Three main TiA layers have been highlighted (Hoff \& Bashir, 2015; Marsh \& Dibben, 2003).

61 The dispositional trust reflects the operator's stable and overall tendency to TiA and

62 depends on factors such as age, gender, culture, and personality traits. The situational

63 trust is influenced by current situational characteristics (e.g., workload, perceived risks)

64 and the operator's contextual mental state (e.g., fatigue, mood). Finally, the learned trust

65 is initially defined by prior experiences, beliefs, and knowledge then dynamically updated

66 during interaction, depending on automation's features and design. These three layers

67 have an increasingly strong influence on the operator's reliance on the automation (Hoff

68 \& Bashir, 2015).

69 The characteristics of the automation, mainly linked to learned trust, are known to

70 influence human-robot trust (Hancock et al., 2011) and some of them have been studied

71 in the context of TiAD using driving simulators or Wizard of $\mathrm{Oz}$ vehicles. For example,

72 aggressive automated driving style seemed to decrease drivers' trust when lawful driving

73 style increased it (Morris et al., 2017). This is coherent with previous results stating that 
74 drivers most often preferred a defensive driving style (Strauch et al., 2019; Yusof et al.,

75 2016). Nevertheless, other studies found no main effect of the driving style, comparing

76 familiar (i.e., close to own manual style) vs. unfamiliar style (Hartwich, Beggiato, et al., 77 2018) or familiar vs. defensive vs. dynamic driving styles (Beggiato et al., 2020). In some

78 case, automated driving had to anticipate and execute actions earlier than the driver 79 would have done (i.e., letting a wider safe distance while overtaking) to get the same 80 declared level of trust (Abe et al., 2018). It was also found that manual driving inspired 81 more trust than automated driving to the passengers (Strauch et al., 2019). These results 82 were later confirmed, showing the lack of familiarity and knowledge about such systems 83 decreased passengers' level of TiAD, compared to a human-control (Schmidt et al., 2021).

84 That may indicate that unexpected and sudden manoeuvres are likely to decrease drivers'

85 TiAD. However, several studies showed Take-Over Requests (TOR) did not decreased 86 trust and increased drivers' understanding of the system. The authors postulated TOR 87 were therefore not considered as automation failures but rather as normal automated 88 driving features in these cases (Hergeth et al., 2015, 2016, 2017). Nevertheless, another 89 study found trust decreased after repeated TOR (Kraus, Scholz, Stiegemeier, et al., 2020), 90 suggesting such critical situations may have a negative impact on TiAD in some cases.

91 Concerning drivers' related factors (influencing dispositional and initial learned trust), 92 studies showed age (Hartwich, Beggiato, et al., 2018; Hartwich, Witzlack, et al., 2018)

93 and personality traits (Kraus, Scholz, \& Baumann, 2020) allowed to predict TiAD in some 94 situation. Initial information given about the system performance may also have an impact 95 on future trust construction (Kraus et al., 2019) because drivers' expectation and mental 96 model are related to TiAD (Beggiato, Pereira, et al., 2015; Forster et al., 2019). Drivers' 
97 trust seems to increase with knowledge about system features (Khastgir et al., 2018), and

98 familiarization with TOR (Hergeth et al., 2017). A promoted TiAD (through textual or video

99 information) was also linked with longer glance towards a non-driving-related task (NDRT)

100 compared to a lowered TiAD (Körber et al., 2018). This engagement in NDRT seems to

101 be a reliable indication of drivers' TiAD, and has been showed to correlate with the level

102 of driving automation (Beggiato, Hartwich, et al., 2015) and the experience with the

103 system (Forster et al., 2020). In addition, a correlation between lower self-reported trust

104 and higher road monitoring have also been exhibited (Hergeth et al., 2016; Payre et al.,

105 2017). Therefore, trust affects not only drivers' performance but also their visual strategies

106 and non-driving related behaviour. Otherwise, initial level of TiAD seems to have an

107 impact on further trust construction and automation use during HAD (Beggiato, Hartwich,

108 et al., 2015; Hartwich et al., 2020), which is the main focus of this paper. The effect of the

109 initial level of TiAD (among Trustful drivers vs. Distrustful drivers) on drivers' behaviour

110 was examined during the early use of a simulated automated driving system, i.e., their 30

111 first minutes of experience with HAD. Because HAD will likely be implemented first for

112 highway use or traffic jam (Wintersberger \& Riener, 2016), and different surveys confirm

113 this idea (Becker \& Axhausen, 2017; Kaur \& Rampersad, 2018), a monotonous highway

114 scenario including two critical situations was used in this study. Trust questionnaires, gaze

115 behaviour and NDRA were analysed.

116 Drivers' declared level of trust is known to increase over time when experiencing driving 117 automation (Bueno et al., 2016; Gold et al., 2015; Hartwich, Witzlack, et al., 2018; Hergeth

118 et al., 2016, 2017; Körber et al., 2018; Kraus, Scholz, Stiegemeier, et al., 2020). In the

119 current experiment, it was thus hypothesized that drivers' level of trust will increase along 
120 with HAD use $(\mathrm{H} 1)$. A low initial level of TiAD might be due to a poor mental model

121 concerning HAD systems, which is likely to be readjusted when drivers experience

122 simulated HAD (Beggiato \& Krems, 2013). It was therefore hypothesized the trust gain

123 will be greater for Distrustful drivers than Trustful drivers $(\mathrm{H} 2)$ and the differences between

124 both groups will still be present at the end of the experiment $(\mathrm{H} 3)$. Moreover, it has been

125 argued that, for a correct trust calibration, operators need to experience system 126 boundaries (Moray \& Inagaki, 1999; Wintersberger et al., 2016). Considering the effect

127 TOR have on drivers' TiAD (Hergeth et al., 2016, 2017; Kraus, Scholz, Stiegemeier, et al., 128 2020), it was expected that the critical situations will have an abrupt negative impact on 129 drivers' trust to be then recovered gradually over time $(\mathrm{H} 4)$.

\section{METHOD}

\section{$131 \quad$ 2.1. Participants}

132 Forty healthy adults (20 females, $M=38$ years old, $S D=8.8$ ) participated in a driving task

133 in a single session. All participants had a valid driver's license for a minimum of three 134 years $(M=18.5, S D=9.3)$ and drove regularly $(M=6.3$ drives per week, $S D=1.6 ; M=$ 13515862 kilometers per year, $S D=12822$ ). Participants' perceived knowledge about AD 136 was assessed during the recruitment process, on a 4-point scale (No knowledge, Basic

137 knowledge, Intermediate knowledge, or Advanced knowledge). Among participants, $12.5 \%$

138 had no knowledge, 50\% a basic knowledge, and $37.5 \%$ an intermediate knowledge. All

139 drivers had normal or corrected-to-normal vision and they received $40 €$ of compensation 140 for their participation. This research complied with the American Psychological 
141 Association Code of Ethics and the European law on General Data Protection Regulation.

142 Informed consent was obtained from each participant.

\subsection{Apparatus}

144 The study was conducted in a static driving simulator equipped with four 32" 16/9 LCD 145 screens giving a $120^{\circ}$ horizontal field of view (Figure 1). The rear view was displayed on 146 three digital mirrors and dashboard information was provided by a 10" $16 / 9$ LCD screen 147 set behind the steering wheel. The driving simulation was controlled by the SCANeR ${ }^{\mathrm{TM}}$

148 Studio software developed by AV Simulation, France (https://www.avsimulation.fr). A 10.1"

149 Xenarc tablet installed in the central console of the simulator was used as HMI. A 150 sideband on the left of the screen included a pictogram informing about the current vehicle 151 state (i.e., "Manual driving", "Available HAD" or "Activated HAD"), a button for HAD 152 activation and specific pictograms when relevant. On the rest of the screen, an Android ${ }^{\mathrm{TM}}$ 153 emulator with some games (e.g., Solitaire, Fruit Ninja, Mahjong) and an internet access

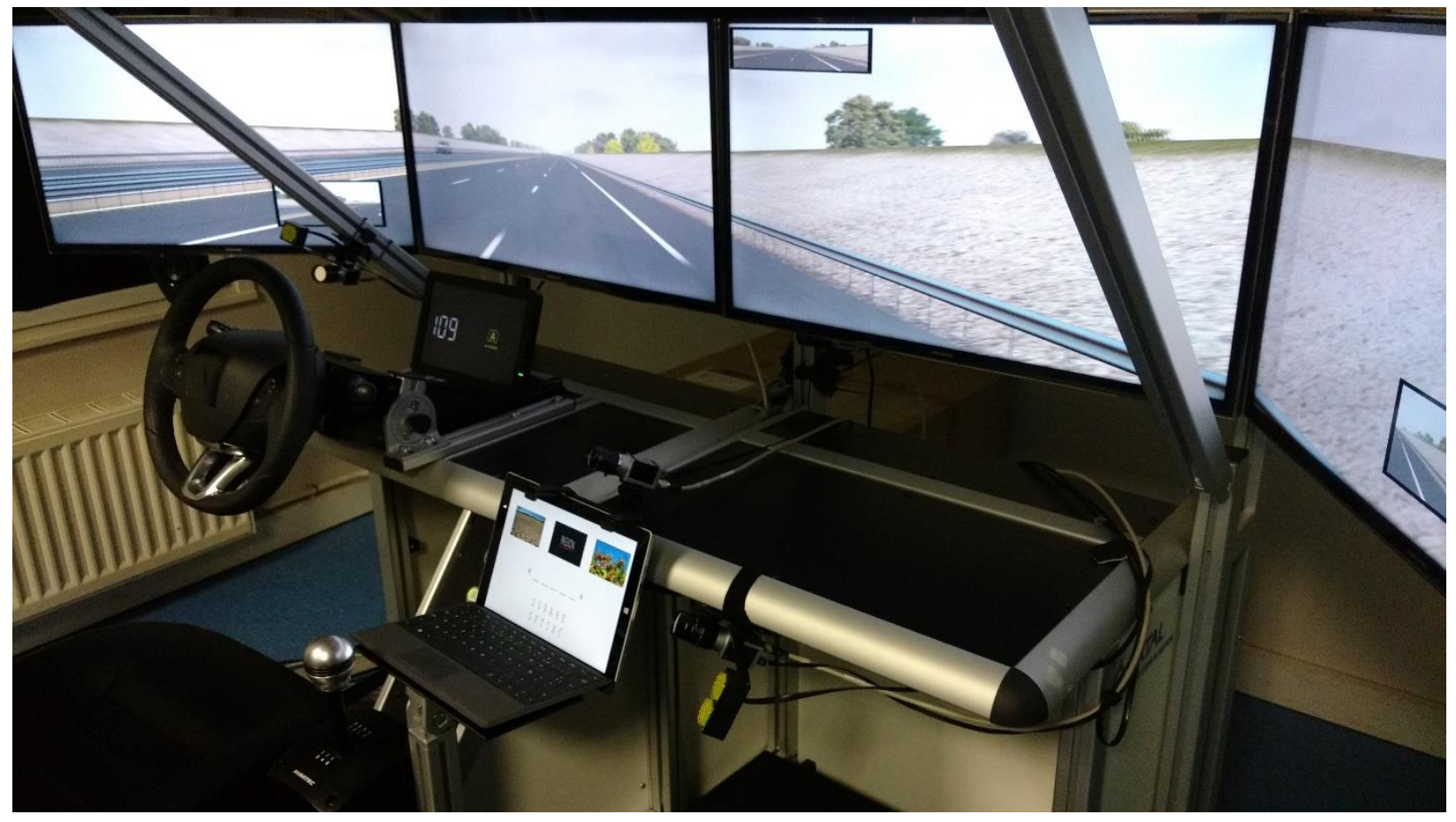

Figure 1. Driving simulator 
154 was displayed. The driver video recording system was composed of four D-Link infrared

155 cameras to investigate visual strategies and NDRA engagement.

$156 \quad$ 2.3. Level of trust assessment

157 Initial level of TiAD was measured using a 10-item questionnaire on a 6-point Likert scale

158 (Table 1) inquiring trust and trust-related dimensions such as perceived safety, intention

159 to use in degraded conditions, and utility. The scale was designed to specifically assess

160 TiAD, in accordance with previous works (see Table 1).

Table 1. Initial level of TiAD assessment scale

\begin{tabular}{|c|c|c|}
\hline & Questions & Origin \\
\hline 1 & I would feel safe in an automated vehicle. & $\begin{array}{l}\text { O'Cass \& Carlson } \\
(2012)\end{array}$ \\
\hline 2 & $\begin{array}{l}\text { The automated driving system provides me with more safety } \\
\text { compared to manual driving. }\end{array}$ & Payre et al. (2016) \\
\hline $3^{*}$ & $\begin{array}{l}\text { I would rather keep manual control of my vehicle than delegate it } \\
\text { to the automated driving system on every occasion. }\end{array}$ & Payre et al. (2016) \\
\hline 4 & I would trust automated driving system decisions. & $\begin{array}{l}\text { O'Cass \& Carlson } \\
(2012)\end{array}$ \\
\hline 5 & $\begin{array}{l}\text { I would trust automated driving system capacities to manage } \\
\text { complex driving situations. }\end{array}$ & $\begin{array}{l}\text { Egea \& González } \\
\text { (2011) }\end{array}$ \\
\hline 6 & $\begin{array}{l}\text { If the weather conditions were bad (e.g., fog, glare, rain), I would } \\
\text { delegate the driving task to the automated driving system. }\end{array}$ & Payre (2015) \\
\hline 7 & $\begin{array}{l}\text { Rather than monitoring the driving environment, I could focus on } \\
\text { other activities confidently. }\end{array}$ & $\begin{array}{l}\text { Egea \& González } \\
\text { (2011) }\end{array}$ \\
\hline 8 & $\begin{array}{l}\text { If driving was boring for me, I would rather delegate it to the } \\
\text { automated driving system than do it myself. }\end{array}$ & Payre et al. (2016) \\
\hline \multirow[t]{2}{*}{9} & $\begin{array}{l}\text { I would delegate the driving to the automated driving system if I } \\
\text { was tired. }\end{array}$ & \multirow[t]{2}{*}{ Payre et al. (2016) } \\
\hline & Not at all $\quad \square \quad \square \quad \square \quad \square \quad \square \quad \square \quad$ Extremely & \\
\hline \multirow[t]{2}{*}{10} & How much do you trust automated driving systems? & \multirow{2}{*}{$\begin{array}{l}\text { Lee and Morray } \\
\text { (1994) }\end{array}$} \\
\hline & $\begin{array}{lllllll}0 \% & \square \quad \square \quad \square \quad \square \quad \square \quad & \square \quad 100 \%\end{array}$ & \\
\hline
\end{tabular}

161 *Answers were inverted for scoring. 
162 Before the experimental session, 90 potential participants were assessed with this scale

163 by email. Homogeneity and internal consistency were good (Cronbach's $\alpha=.93$,

164 McDonald's $\omega \mathrm{h}=.78$, and $\omega t=.96)$.

165 A k-means clustering method split them in two groups: Trustful drivers (high initial level of 166 trust) and Distrustful drivers (low initial level of trust). The 20 most extreme participants of 167 each group were selected: Trustful drivers $(n=20,6 F / 14 M, M=39.55$ years old, $S D=$ $1689.09)$ and Distrustful drivers $(n=20,14 F / 6 M, M=36.50$ years old, $S D=8.50)$. These 169 trust scores served to establish participants' initial level of TiAD. The same scale 170 formulated in past tense was used to assess final level of trust at the end of the 171 experiment.

172 Dynamic level of trust was measured using a Single Trust Item ("I trusted automated 173 driving system decisions.", item 3 from the previous scale, Table 1) on a 6-point Likert 174 scale to investigate current drivers' level of trust after each scenario (Lee \& Moray, 1994; 175 Seppelt \& Lee, 2019).

\section{$176 \quad$ 2.4. Procedure}

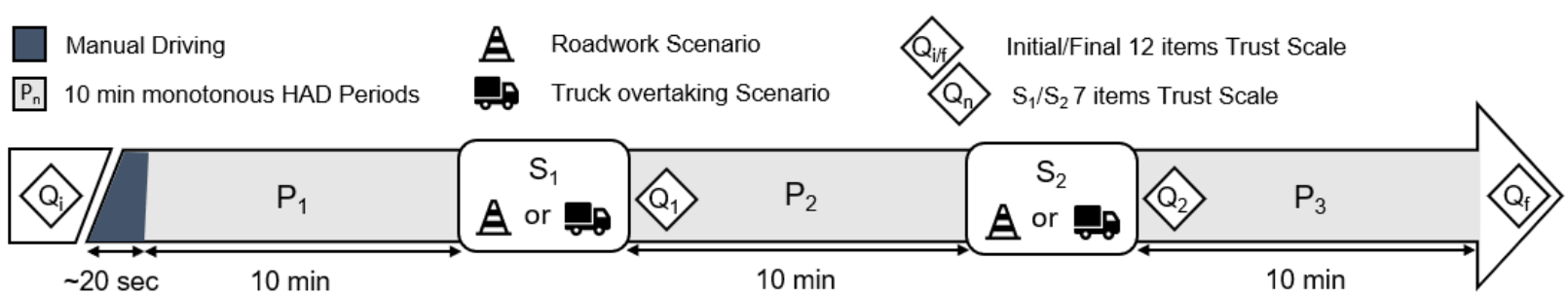

Figure 2. Experimental protocol

177 Participants arrived at VEDECOM Institute and signed a consent form. They received a

178 ten-minute practice to familiarize themselves with the driving simulator, and the 179 automated driving (e.g., HAD activation, vehicle manoeuvres during non-critical situations, 
180 pictograms, HMI, sounds). During the experimental task, participants activated HAD after 181 merging into the highway. The vehicle speed was set at $130 \mathrm{~km} / \mathrm{h}$ (the maximum allowed 182 speed on French highways) on a three-lane highway, in a low-density traffic (3-6 vehicles 183 per kilometre). Manual take-over was not possible to ensure that all participants 184 experienced the same scenarios, and they were free to engage in NDRA (e.g., reading, 185 texting, using the Android ${ }^{\mathrm{TM}}$ tablet, listening to the radio). After ten minutes of monotonous 186 automated driving $\left(\mathrm{P}_{1}\right)$, participants were confronted with the first scenario $\left(\mathrm{S}_{1}\right)$, indicated 187 by a sound and a specific pictogram 5 seconds before the event and they completed the 188 first Single Trust Item right after $\left(Q_{1}\right)$. The scenario was a roadwork area, signalled by 189 traffic cones and a roadwork van. The vehicle strongly decelerated from $130 \mathrm{~km} / \mathrm{h}$ to 90 $190 \mathrm{~km} / \mathrm{h}$, at about $6 \mathrm{~m} / \mathrm{s}^{2}$ until the Time to Collision (TTC) with the roadwork area was 2.5 191 sec. It then changed from right lane to left lane and returned to the right lane after 192 overtaking the obstacles. After the second ten-minute monotonous automated driving $\left(\mathrm{P}_{2}\right)$, 193 the second scenario $\left(S_{2}\right)$ happened, indicated by the same sound and a specific 194 pictogram 5 seconds before the event, and followed by the second Single Trust Item (Q2). 195 This scenario was represented by a slow leading truck $(90 \mathrm{~km} / \mathrm{h})$ driving on the right lane, 196 forcing the vehicle to decelerate from $130 \mathrm{~km} / \mathrm{h}$ to $90 \mathrm{~km} / \mathrm{h}$ (at about $7 \mathrm{~m} / \mathrm{s}^{2}$, until the TTC 197 with the truck was $1.5 \mathrm{sec}$ ), as the left lane was occupied. Once the left lane was cleared, 198 the vehicle overtook the truck and returned to the right lane. The order of presentation of 199 the scenarios was counterbalanced. Finally, the third ten-minute period of monotonous 200 driving $\left(\mathrm{P}_{3}\right)$ and the final 10-item trust scale $\left(\mathrm{Q}_{\mathrm{f}}\right)$ terminated the experimental session 201 (Figure 2). Participants were then interviewed for approximately 10 minutes about their 202 overall feeling concerning the experiment and their behaviour during HAD. 
204 Dependent variables included declared trust, glance count, glance duration and NDRA 205 engagement frequency.

206 Trust scale were scored by adding each answer (reversing item 3, cf. Table 1). Scores 207 were then converted in percentage $\left(s=\left(a_{1}+a_{2}+\left(7-a_{3}\right)+a_{4}+a_{5}+a_{6}+a_{7}+a_{8}+\right.\right.$ $\left.\left.208 a_{9}+a_{10}-10\right) \div 50 \times 100\right)$. Single Trust Item were converted in percentage $(s=$ $\left.209\left(a_{4}-1\right) \div 5 \times 100\right)$. To compare overall trust evolution, the fourth item from Initial and 210 Final scales (the Single Trust Item) was used.

211 Visual strategies and NDRA data were processed by manual video-coding every tenth of

212 a second. For each change in gaze direction, one glance to the previously monitored area 213 was accounted (glance count), and the glance duration was added to the total glance 214 duration towards this area, then transformed in percentage of the total glance time (glance 215 duration). Areas of interest were defined as "Road”, "Rear Mirrors", "Dashboard”, "NDRA", 216 "HMI Sideband", "Tablet" and "Other" for all glances directed somewhere else. "Road", 217 "Rear Mirrors", "HMI Sideband", and "Dashboard” were grouped in a category "Driving 218 environment" for analysis.

219 NDRA categories were defined based on participants' most frequently observed activities:

220 "Environment monitoring" when participants did nothing but monitor the driving 221 environment, "Mobile phone use", "Tablet use", "Reading", and "Radio use". The other 222 minor activities (e.g., grooming, drinking water, put glasses on) were combined in a new 223 category "Other".

224 Data and graphics were processed using R (R Core Team, 2017) and ggplot2 (Wickham, 225 2016). 


\section{RESULTS}

\subsection{Declarative trust}

228 The mean trust scores for the different questionnaires are reported in Table 3.

Table 3. Mean trust scores (\%) for the Single Trust Items.

\begin{tabular}{rrrrrr}
\hline \multirow{2}{*}{ Time } & \multirow{2}{*}{ Group } & \multirow{2}{*}{ Mean } & \multirow{2}{*}{ SD } & \multicolumn{2}{c}{ 95\% Cl } \\
\cline { 5 - 6 } & & & & Low & High \\
\hline Initial Single & Trustful & 74 & 16.03 & 66.97 & 81.03 \\
Trust Item & Distrustful & 37 & 13.42 & 31.11 & 42.88 \\
\hline $1^{\text {st }}$ Scenario & Trustful & 81 & 23.82 & 70.56 & 91.43 \\
& Distrustful & 45 & 37.77 & 28.44 & 61.55 \\
\hline $2^{\text {nd }}$ Scenario & Trustful & 79 & 24.69 & 68.17 & 89.82 \\
& Distrustful & 46 & 31.19 & 32.33 & 59.66 \\
\hline Final Single & Trustful & 86 & 14.65 & 79.57 & 92.42 \\
Trust Item & Distrustful & 57 & 28.49 & 44.51 & 69.48 \\
\hline
\end{tabular}

A two-way mixed-design ANOVA (Group x Time, 2 levels: Initial assessment and Final

231 assessment) was performed to investigate the effect of the experience on trust

232 construction in Trustful and Distrustful drivers (Figure 3). There was a significant effect of 233 the Group, $F(1,38)=77.6, p<.001, n p^{2}=.671$, and the Time, $F(1,38)=29.3, p<.001$,

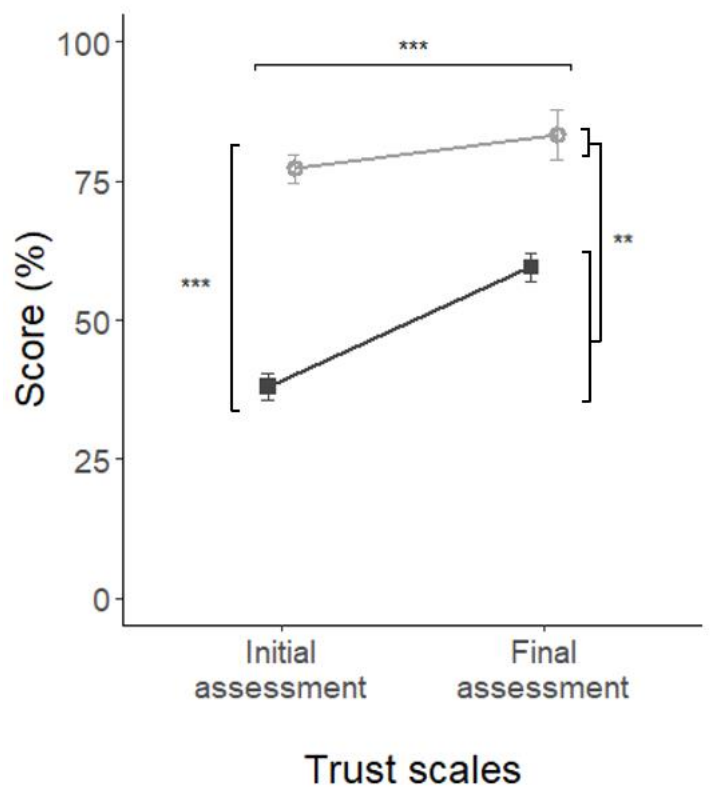

Figure 3. Initial and Final trust scales. 
$234 \eta p^{2}=.436$. The interaction Groupe $x$ Time was also significant, $F(1,38)=9.32, p<.01$,

$235 \eta p^{2}=.197$. In short, declared trust was found to increase for both Trustful and Distrustful

236 participants during the interaction with the vehicle $(\mathrm{H} 1)$, and the trust increase was higher

237 for Distrustful drivers (H2).

238 Another two-way mixed-design ANOVA (Group x Time, 4 levels: Initial assessment, $1^{\text {st }}$

239 Scenario $\left(S_{1}\right), 2^{\text {nd }}$ Scenario $\left(S_{2}\right)$ and Final assessment) was performed to investigate

240 scenarios' impact on drivers' early trust construction (Figure 4). There was a significant

241 effect of the Group, $F(1,38)=32.7, p<.001, \eta_{p}^{2}=.462$, and the Time, $F(3,114)=4.11$,

$242 p<.01, \eta_{p}^{2}=.098$. Post hoc tests using Bonferroni correction showed that the Initial

243 assessment differed significantly from Final assessment $(p<.001)$, but no other

244 comparisons were significant. As expected, the differences between both groups were

245 significant in the final assessment $(p<.001)$, confirming H3.

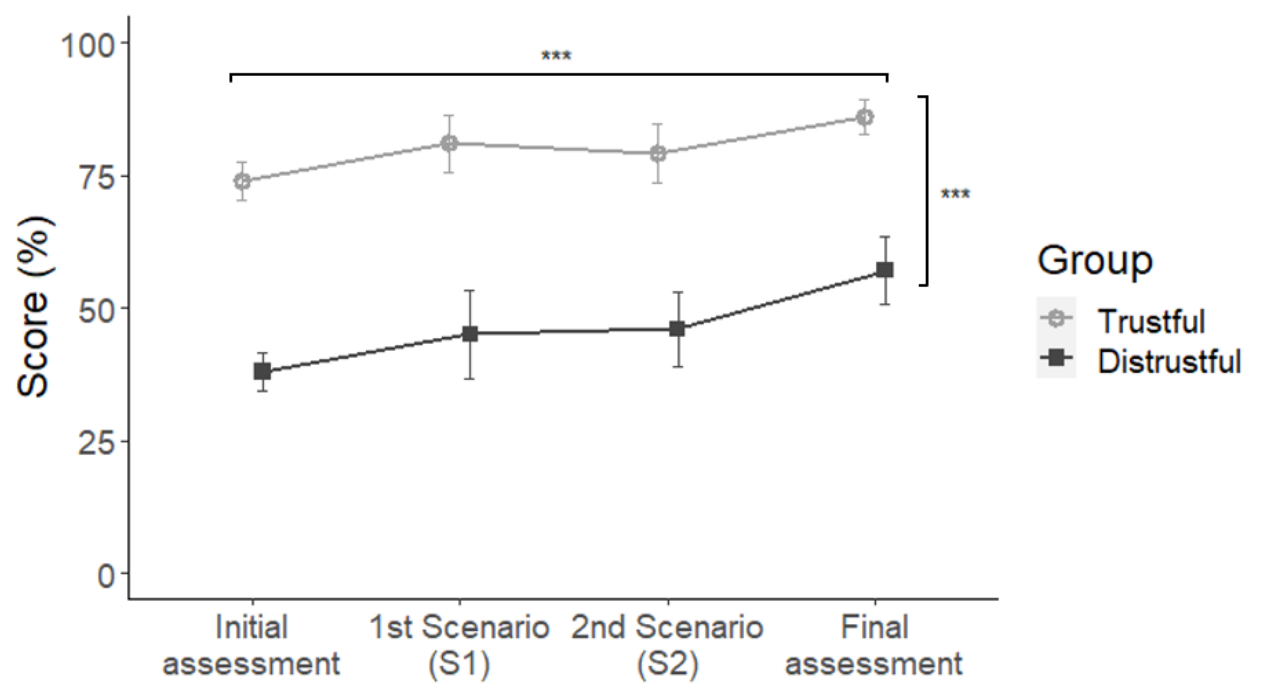

Trust scales

Figure 4. Declared level of TiAD evolution on Single Trust Items; error bars = standard error

246 Motivated by the differences in trust reported by participants concerning the two scenarios

247 (62.5\% of the participants declared Truck scenario as more critical, $20 \%$ Roadwork 


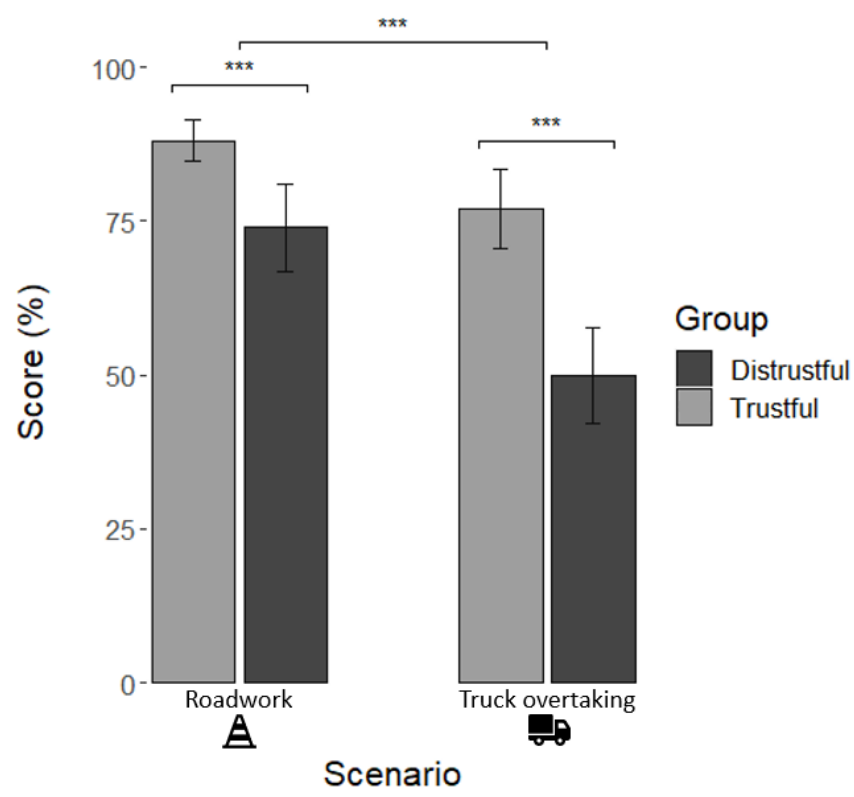

Figure 5. Declared level of TiAD depending on the Scenario; error bars $=$ standard error

248 scenario, $17.5 \%$ did not feel any difference), a two-way mixed design ANOVA was 249 conducted (Group x Scenario type, 2 levels: Roadwork scenario vs. Truck scenario) 250 (Figure 5). There was a significant effect of the Scenario type, $F(1,38)=11.86, p<.001$, $251 \eta_{p}^{2}=.238$ for both Trustful $(p<.001)$ and Distrustful $(p<.001)$ confirming that drivers 252 reported less trust after the Truck scenario than after the Roadwork scenario.

253 Data were therefore separated to analyse whether this difference had an impact on early 254 trust construction (Figure 6). A three-way mixed-design ANOVA (Group x Time $\times$ Scenario 255 Order, 2 levels: Roadwork $\rightarrow$ Truck vs. Truck $\rightarrow$ Roadwork) showed a main effect of the 256 Group, $F(1,36)=32.8, p<.001, \eta_{p}^{2}=.476$, and Time, $F(3,108)=5.29, p<.001$, $257 \eta_{p}^{2}=.128$. The main effect of Scenario Order was not significant, $F(1,36)=.007, p>.05$, $258 \eta_{p}^{2}=.000$ 
259 The interaction between Scenario Order and Time was significant, $F(3,108)=11.0$, $260 p<.001, \eta_{p}^{2}=.234$. This revealed that, in sequence Roadwork $\rightarrow$ Truck, Initial 261 assessment differed from $S_{1}(p<.001)$ and $S_{2}$ differed from Final assessment $(p<.001)$, 262 but in sequence Truck $\rightarrow$ Roadwork, Initial assessment differed from $\mathrm{S}_{2}(p<.01)$. In short, 263 early trust construction was found to differ according to Scenario Order for both Trustful 264 and Distrustful participants.

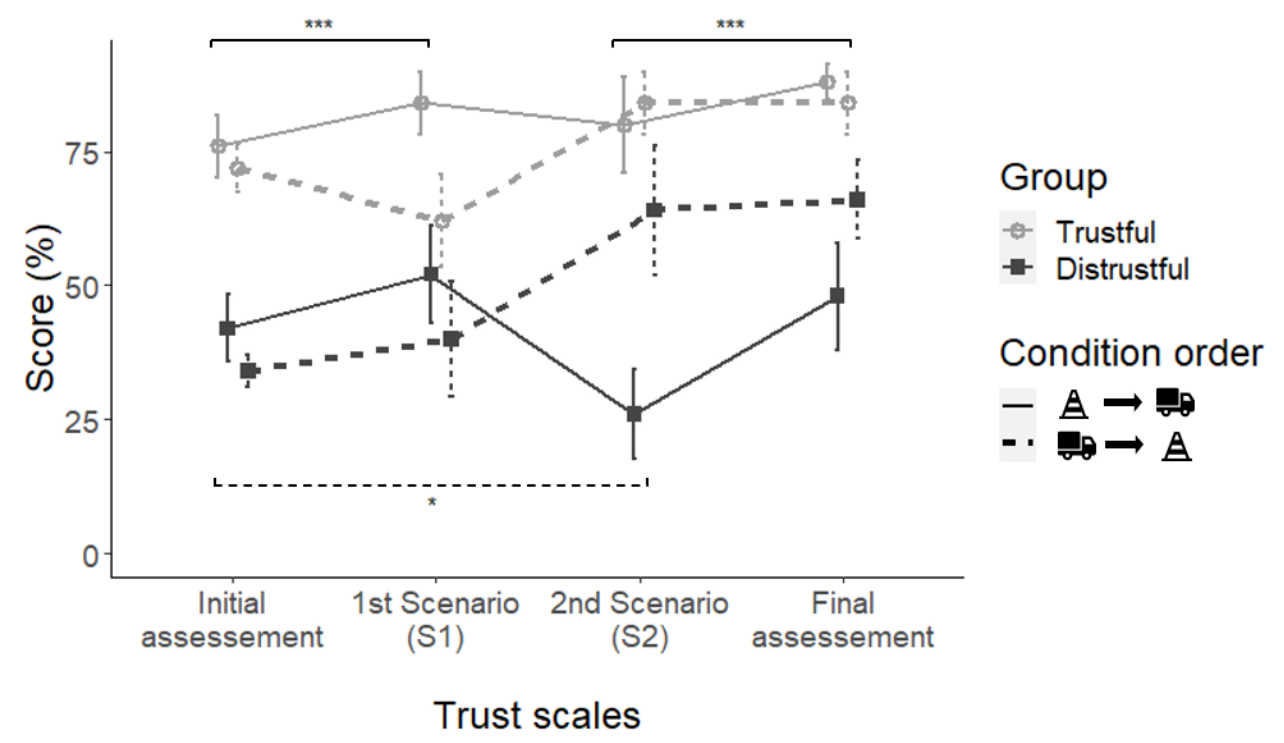

Figure 6. Declared level of TiAD evolution, depending on the Scenario Order; error bars = standard error

\subsection{Visual behaviour}

266 Due to technical problems, two Trustful participants were excluded from the analysis. A 267 two-way mixed-design ANOVA (Group $x$ Driving Period, 3 levels: $P_{1}$ vs. $P_{2}$ vs. $P_{3}$ ) was 268 conducted on glance count and glance duration. During monotonous driving, there was 269 only a main effect of the Driving Period on glance count towards the Driving environment 270 (Road, Rear-mirrors and Dashboard), $F(2,72)=18.6, p<.001, \eta_{\mathrm{p}}^{2}=.341$ (Figure 7), and 271 towards the NDRA, $F(2,72)=3.54, p<.05, \eta_{p}^{2}=.090$ (Figure 8). A post hoc test showed 272 that glance count towards the Driving environment was reduced between $\mathrm{P}_{1}$ and $\mathrm{P}_{2}(p$ 
$273<.001)$. In short, drivers' number of eyes movements decreased during HAD for both 274 groups.

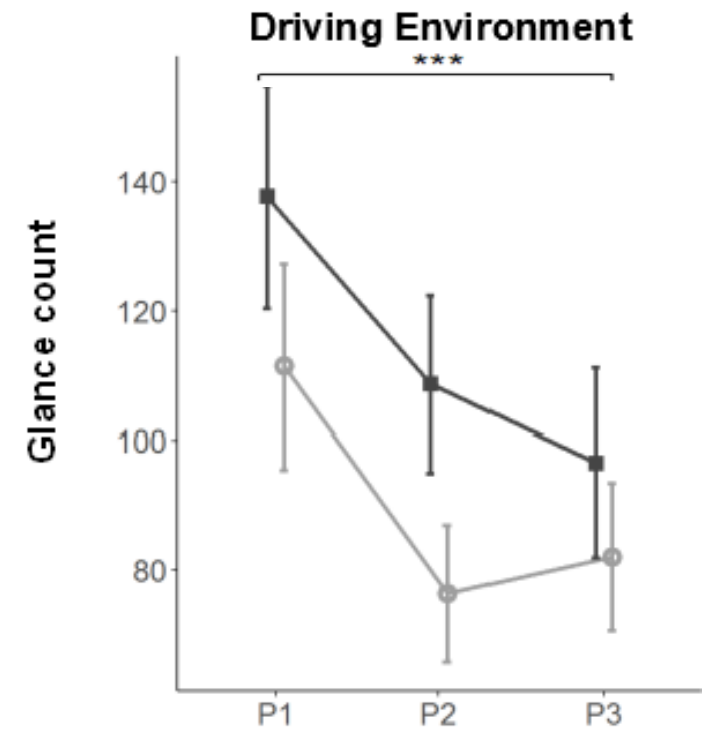

Automated driving period

Figure 7. Glance count towards the driving environment during the automated Driving Periods; error bars = standard error

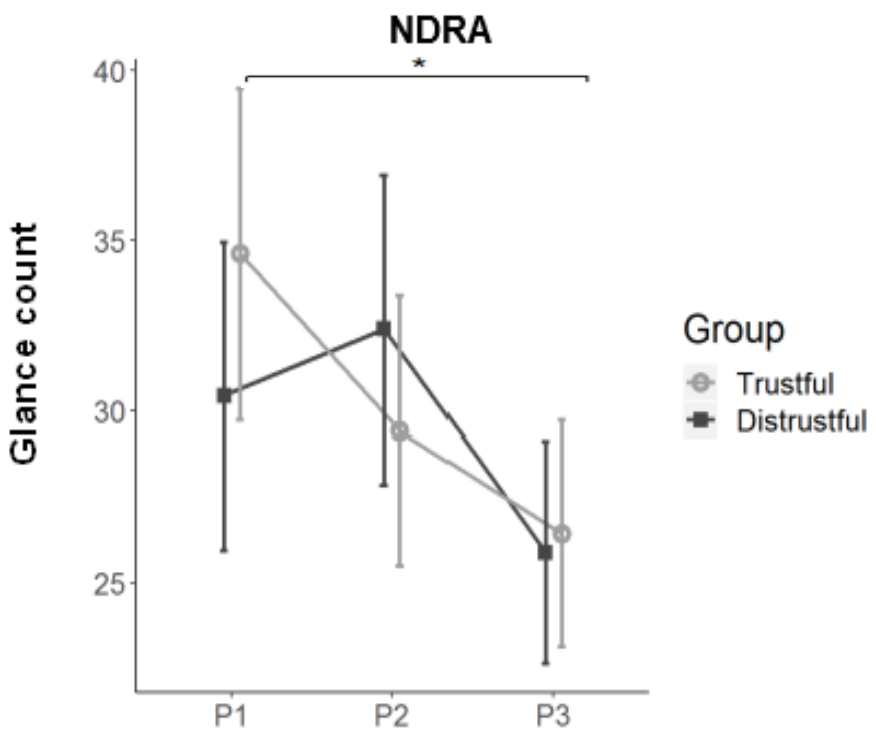

Automated driving period

Figure 8. Glance count towards the NDRA during the automated Driving Periods; error bars = standard error

275 Concerning glance duration towards the Driving environment, results showed a main

276 effect of the Group, $F(1,36)=4.64, p<.05, \eta_{p}^{2}=.114$ and a main effect the Driving

277 Period, $F(2,72)=4.28, p<.05, \eta_{p}^{2}=.106$ (Figure 9). A post hoc test showed that glance

278 duration was reduced between $\mathrm{P}_{1}$ and $\mathrm{P}_{2}(p<.05)$. There were no significant differences

279 concerning glance duration towards NDRA (Figure 10). In short, drivers monitored road

280 less frequently and during less time $(\mathrm{H} 1)$ over HAD and particularly during the first ten

281 minutes. Distrustful drivers tent to check the driving environment during more time than

282 Trustful drivers $(\mathrm{H} 3)$. 


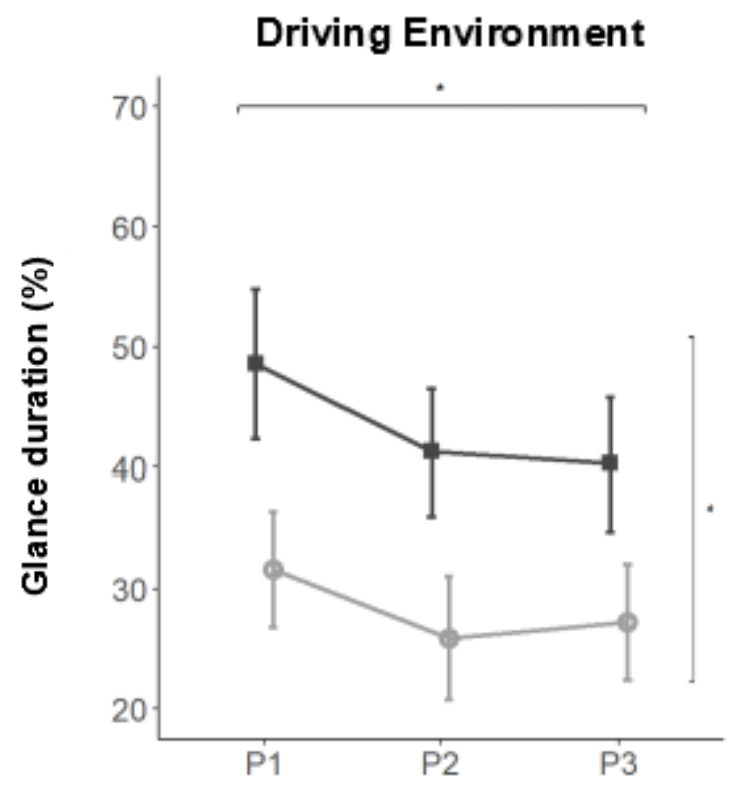

Automated driving period

Figure 9. Proportion of glance duration (\%) towards the driving environment during the automated Driving Periods; error bars = standard error

283 In order to evaluate the visual behaviour evolution over time, a binary logistic regression

284 with repeated measures (logit) opposing glances towards the driving environment (Road, 285 Mirrors, and Dashboard) to all glances directed elsewhere (NDRA, Android ${ }^{\mathrm{TM}}$ tablet, and $^{2}$ 286 Other) was conducted. Temporal variables were time (squared) and 3 variables 287 constructed from simple, squared, and cubed values of the distance to each of the 288 Scenarios $\left(S_{1} \& S_{2}\right)$.

289 The final model (Table 4, Figure 11) includes all the variables described above. The logit 290 was controlled with Group, Gender and Conditions order. Reference variables are 291 indicated in italic. Due to the high number of observations in the model, the $p$-values may 
292 be higher than they would be with ANOVAs. The dynamic of the variation, on the other 293 hand, can be fully considered.

Table 4. Influence of specific periods of time on glances directed towards the driving environment between Trustful and Distrustful drivers

Trustful

\begin{tabular}{lcc} 
& $\beta$ & Odds ratio \\
\hline (Intercept) & $4.672^{* * *}$ & 106.963 \\
Female & $-2.120^{*}$ & 0.120 \\
Distrustful & $2.080^{*}$ & 8.008 \\
Time $\left({ }^{2}\right)$ & $-0.113^{* * *}$ & 0.893 \\
Interaction Time $\left({ }^{2}\right) \times$ Group & $0.007^{* * *}$ & 1.007 \\
Condition A $\rightarrow$. & -0.937 & 0.391 \\
Distance to Scenario & $1.348^{* * *}$ & 3.849 \\
$\quad$ Distance to $\mathrm{S}_{1}$ & $-2.152^{* * *}$ & 0.116 \\
Distance to $\mathrm{S}_{1}\left({ }^{2}\right)$ & $1.098^{* * *}$ & 2.999 \\
$\quad$ Distance to $\mathrm{S}_{1}\left({ }^{3}\right)$ & $1.364^{* * *}$ & 3.911 \\
Distance to $\mathrm{S}_{2}$ & $-3.533^{* * *}$ & 0.029 \\
$\quad$ Distance to $\mathrm{S}_{2}\left({ }^{2}\right)$ & $2.509^{* * *}$ & 12.301 \\
$\quad$ Distance to $\mathrm{S}_{2}\left({ }^{3}\right)$ & \multicolumn{2}{c}{521415.4} \\
\hline AlC & \multicolumn{2}{c}{564787} \\
ROC & \multicolumn{2}{c}{}
\end{tabular}

294

295 The results of this model (Table 4, Figure 11) showed again that the probability to look

296 towards the driving environment during critical scenarios was higher for Distrustful drivers

297 than for Trustful drivers. Moreover, the probability to look towards the driving environment

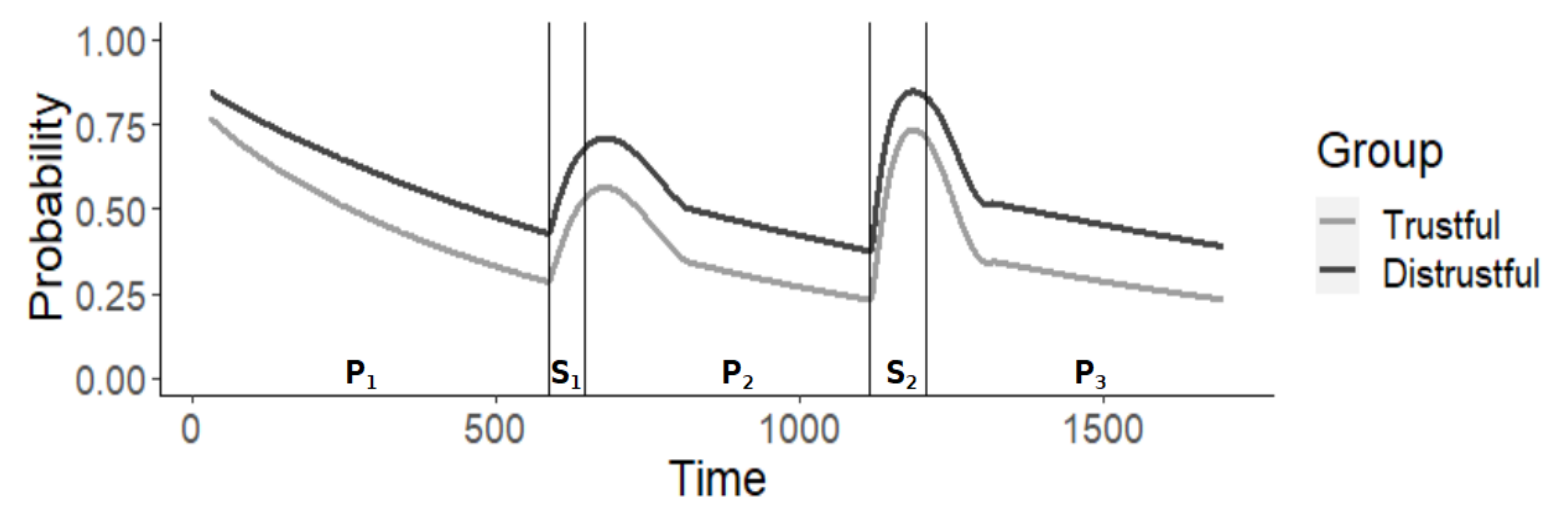

Figure 11. Evolution of the probability to look towards the driving environment over time. 
298 was higher immediately after the scenarios than during the next driving period (for both 299 drivers). These results confirmed the $\mathrm{H} 4$.

\subsection{Non-driving-related activities}

301 Due to technical problems, two Trustful participants were excluded from the analysis. Two 302 participants (1 Trustful and 1 Distrustful) did not engage in NDRA at all. During HAD, 303 participants monitored the driving environment $21.9 \%$ of their time. The rest of the time, 304 the most frequent NDRA they engaged in were mobile use for texting, calling, playing or 305 web browsing (33.6\%), tablet use for playing games and web browsing (17\%), reading 306 magazines or other documents $(14.2 \%)$, and listening to the radio $(3.75 \%)$. Other minor 307 activities represented $9.15 \%$ of participants' time (Figure 12). A chi-square test of 308 independence between Group and NDRA engagement was significant, $\chi^{2}(5, N$ $309=38)=27.272, p<.001$. Distrustful drivers were more likely to monitor the driving

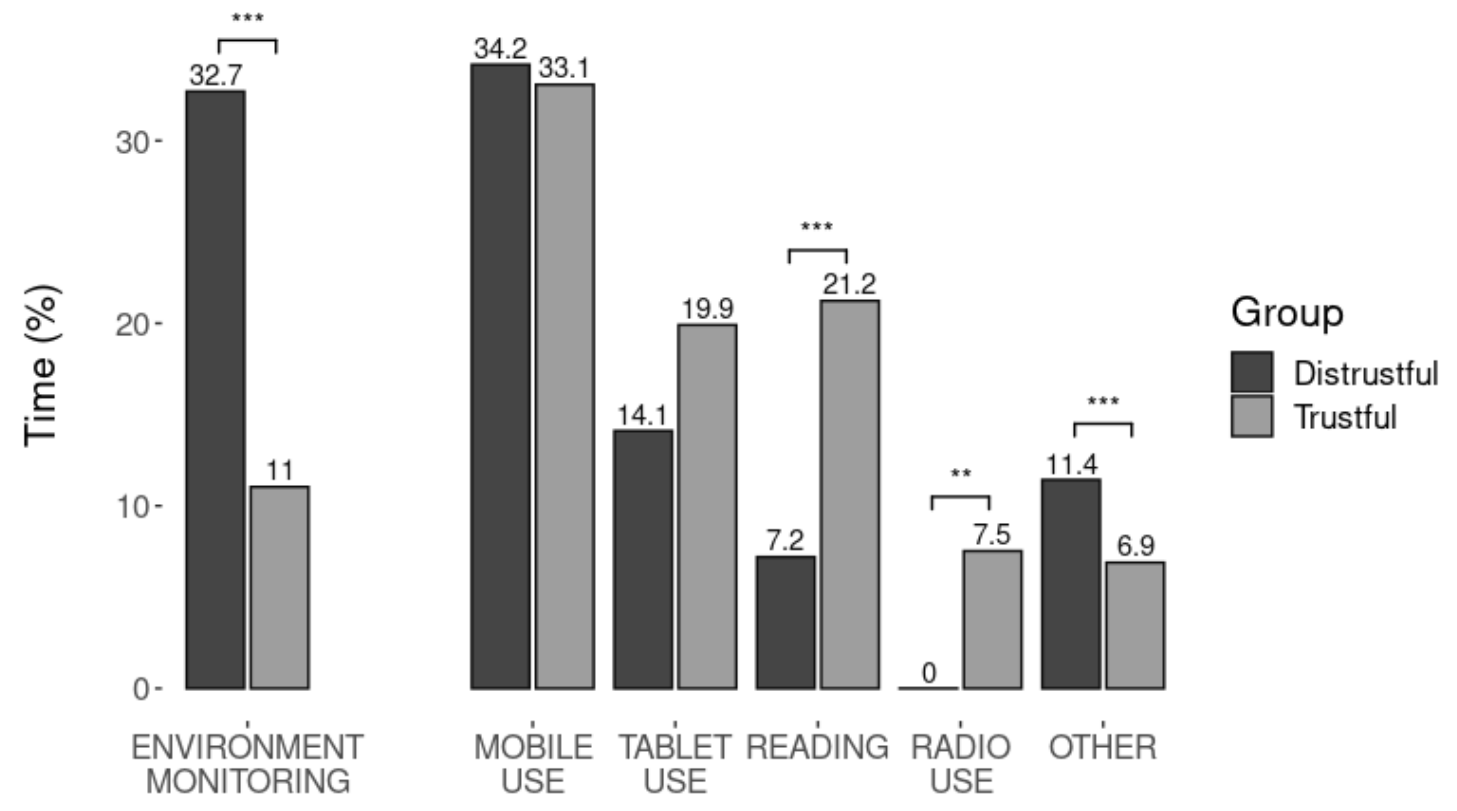

Non-Driving Related Activities

Figure 12. Drivers' environment monitoring and NDRA engagement during HAD. 
310 environment and less likely to engage in some NDRA (i.e., reading, radio use) than were

311 Trustful drivers $(\mathrm{H} 2)$.

\section{4. Discussion}

313 The current study aimed to investigate the impact of (a) drivers' initial level of TiAD, (b)

314 simulated HAD experience and, (c) safety critical situations on drivers' trust during the

315 first interactions with automated driving. Drivers' early trust construction during these 30

316 minutes drives was examined through questionnaires, visual behaviours, and non-driving

317 related activities.

\subsection{Impact of initial level of TiAD}

319 Reported trust was found to be consistently lower for Distrustful drivers than for Trustful 320 drivers at each of the four assessments of trust made during the experiment. This result 321 could indicate that pre-existing knowledge or beliefs influencing initial learned trust (Hoff

322 \& Bashir, 2015) can have a persistent effect on drivers' early trust construction during

$323 \mathrm{HAD}$. It therefore seems that 30 minutes of HAD is not enough to erase the difference in

324 level of trust between Distrustful and Trustful drivers. A longer HAD experience may be

325 needed to outweigh this initial level of trust, as shown in longer studies in other human-

326 machine interaction contexts (Mayer, 2008; Sauer et al., 2015). In addition, although

327 reported trust increased for both groups (9\% in Trustful drivers and $38 \%$ in Distrustful

328 drivers), participants declared differences in HAD perception, expectation and use

329 intention. Thus, most of Distrustful drivers felt uncomfortable with the idea of using

330 automated driving on road while Trustful drivers were enthusiastic about the NDRA

331 engagement possibilities. The initial level of trust may therefore be used as a good

332 indicator of HAD use and driver's behaviour in the early use of automated driving, and 
333 car manufacturers should take this initial level of trust into account to provide the best

334 feedbacks to drivers, depending on their needs.

335 Drivers' visual strategies were consistent with declared level of trust: Distrustful drivers 336 spent $43.4 \%$ of their time monitoring the road while Trustful drivers only spent $28.3 \%$. This

337 confirms previous founding from Hergeth et al. (2016). Accordingly, time allocated to

338 NDRA showed the inverse pattern (50\% of the time among Distrustful drivers vs. $62.8 \%$

339 among Trustful drivers) which is consistent with Körber et al. (2018)'s results. Drivers'

340 NDRA engagement confirmed the influence of the initial level of TiAD, as Distrustful

341 drivers engaged less in some activities (e.g., reading, using the radio) and were more

342 likely to monitor the driving environment. This brings new elements to support the

343 comprehension of initial learned trust influence on early trust construction (Hoff \& Bashir,

344 2015) in the context of HAD. Finally, the regression model showed an impact of the

345 gender on gaze behaviours. Such effect was not found in other analyses (i.e., scores and

346 NDRA engagement), nor in other studies (Feldhütter et al., 2016; Molnar et al., 2018;

347 Schwarz et al., 2019). Yet, the imbalance in female/male distribution in both groups may

348 have had an impact on these results, and further studies are needed to clarify the link

349 between gender and initial level of trust.

$350 \quad$ 4.2. Impact of HAD experience

351 Reported trust was found to increase over time, particularly during the first 10 minutes of 352 the experiment. This is coherent with previous results showing an overall positive effect 353 of the simulated HAD on trust (Gold et al., 2015; Hergeth et al., 2016). Similarly, Hartwich 354 et al. (2018) observed a strong increase in trust during the first interaction with the system, 355 followed by a stabilization. Glance behaviours are known to be modified by driving 
356 automation introduction (e.g., Navarro et al., 2016, 2017, 2019). It was found in this

357 experiment that participants glance behaviour changed over the driving session, in a

358 similar way for both groups. Glance count towards the driving environment decreased by

$35928 \%$ while glance count towards NDRA decreased by $20 \%$. This overall decreasing trend

360 in glance count combined with a decrease in glance duration towards the driving

361 environment indicated a change in drivers' visual strategy. Participants seemed not only

362 to monitor less the road, but also to experience increasing periods of fixed gaze. This may

363 indicate an increase in trust but may also be the result of a drivers' habituation to the

364 driving simulation. Nevertheless, these data are coherent with previous results (Hergeth

365 et al., 2016) and statements about trust influence on automation monitoring (e.g., Muir \&

366 Moray, 1996). This information raises concerns about drivers' ability to take manual

367 control back in urgent situations if their mental representation of the surrounding 368 environment is not up to date.

\section{4.3. Impact of critical situations}

370 The two scenarios presented in this experiment were realistic, common driving situations.

371 Although scenarios were designed to be similar, they were perceived differently.

372 Therefore, dissociating both scenarios provided information about how perceived safety

373 may impact early trust construction. The results suggested that trust evolves differently

374 depending on the exposure to critical situations. If drivers are exposed to a more critical

375 situation at the very first interaction with automated driving, trust will not increase but will

376 remain stable, to then grow gradually after a situation perceived as less dangerous. This

377 may indicate that drivers are calibrating their trust and therefore are carefully observing

378 the next AV action. Conversely, if the first interaction is perceived as safer than the second, 
379 trust is likely to increase significantly (potentially leading to over-trust) but also to return

380 to its initial level after the second event. This supports results from Walker et al. (2019)

381 about the importance of early interaction in TiAD construction. Trust calibration seems

382 indeed more irregular and this reduction in TiAD may lead to a manual recovery (Payre,

383 Cestac, \& Delhomme, 2016), possibly resulting in a poorly realized manoeuvre.

384 These results indicate that first experiences with automated driving systems may have a 385 stronger influence on short-term trust calibration. Proper driver's training for automated 386 driving is a current issue in human factors (Payre et al., 2016; Wintersberger et al., 2016).

387 Our results suggest that it may be valuable to experience critical situation during the first 388 interactions with automated driving, particularly for Distrustful people, in order to improve 389 drivers' trust calibration. Nonetheless, given the small number of participants in each 390 condition, this finding needs to be confirmed by further research.

\subsection{Limitations and perspectives}

392 In this experiment, take-over control of the vehicle was not allowed to guarantee that all 393 participants experienced both scenarios. This methodological choice increased 394 experimental control but was less natural, as participants could not return in manual 395 control. Other studies are also required to investigate the influence of critical situations 396 timing, during one or more sessions. As stated by Hoff and Bashir (2015), system 397 malfunctions or operators' experience with the system may impact learned trust. Here, 398 each condition occurred after ten minutes of HAD, in a single session, however, trust 399 might evolve differently after longer HAD periods of use, multiple driving sessions or a 400 higher number of critical scenarios experienced during HAD. Furthermore, it may be 401 valuable to investigate the impact of other trust factors (Hoff \& Bashir, 2015), such as 
402 different driving environments or mental workload on drivers' behaviour during HAD use.

403 Moreover, simulated environment provided a widely replicable experiment, but decreased

404 participants perceived risk. On-road studies may explore TiAD related factors with a less

405 biased participants' safety feeling.

\section{5. CONCLUSION}

407 This study confirms previously established relations between self-reported trust and road

408 monitoring during HAD and give some hints on possible drivers' NDRA engagement

409 following HAD. It provides additional insight into the influence of initial level of trust on

410 further trust development during the first interactions with HAD. It also shows that drivers

411 with high initial levels of TiAD are more likely to engage in NDRA, compared to drivers

412 with low initial levels of TiAD. These initial levels of trust may influence the kind of NDRA

413 drivers engage in, as Trustful drivers seems to be more prone to read than Distrustful one.

414 Car manufacturers should be aware of these effects and may use simulated HAD to help

415 drivers to calibrate an appropriate level of TiAD depending on the capabilities of a 416 particular HAD system. 


\section{ACKNOWLEDGMENTS}

418 We wish to thank Romane Beaufort for her advice on statistical analyses, and five 419 anonymous reviewers for their helpful comments on a previous version of this work.

420

421 Funding: This study was supported by VEDECOM Institute, "Institute for Energy 422 Transition" and part of the French governmental plan "Investment for the Future" (ANR423 10-IEED-0009).

424

425 The authors declare that they have no known competing financial interests or personal 426 relationships that could have appeared to influence the work reported in this paper. 


\section{References}

428

429

430

431

432

433

434

435

436

437

438

439

440

441

442

443

444

445

446

447

Abe, G., Sato, K., \& Itoh, M. (2018). Driver Trust in Automated Driving Systems: The Case of Overtaking and Passing. IEEE Transactions on Human-Machine Systems, 48(1), 85-94. https://doi.org/10.1109/THMS.2017.2781619

Beggiato, M., Hartwich, F., Roßner, P., Dettmann, A., Enhuber, S., Pech, T., Gesmann-Nuissl, D., Mößner, K., Bullinger, A. C., \& Krems, J. (2020). KomfoPilot-Comfortable Automated Driving. In G. Meixner (Ed.), Smart Automotive Mobility: Reliable Technology for the Mobile Human (pp. 71-154). Springer International Publishing. https://doi.org/10.1007/978-3-030-45131-8_2

Beggiato, M., Hartwich, F., Schleinitz, K., Krems, J., Othersen, I., \& Petermann-Stock, I. (2015). What would drivers like to know during automated driving? Information needs at different levels of automation. https://doi.org/10.13140/RG.2.1.2462.6007

Beggiato, M., \& Krems, J. F. (2013). The evolution of mental model, trust and acceptance of adaptive cruise control in relation to initial information. Transportation Research Part F: Traffic Psychology and Behaviour, 18, 47-57. https://doi.org/10.1016/j.trf.2012.12.006

Beggiato, M., Pereira, M., Petzoldt, T., \& Krems, J. (2015). Learning and development of trust, acceptance and the mental model of ACC. A longitudinal on-road study. Transportation Research Part F: Traffic Psychology and Behaviour, 35, 75-84. https://doi.org/10.1016/j.trf.2015.10.005

Bueno, M., Dogan, E., Selem, F. H., Monacelli, E., Boverie, S., \& Guillaume, A. (2016). How different mental workload levels affect the take-over control after automated driving. 
Intelligent Transportation Systems (ITSC), 2016 IEEE 19th International Conference On, 2040-2045.

Feldhütter, A., Gold, C., Hüger, A., \& Bengler, K. (2016). Trust in Automation as a Matter of Media Influence and Experience of Automated Vehicles. Proceedings of the Human Factors and Ergonomics Society Annual Meeting, $60(1)$ 2024-2028. https://doi.org/10.1177/1541931213601460

Forster, Y., Geisel, V., Hergeth, S., Naujoks, F., \& Keinath, A. (2020). Engagement in Non-Driving Related Tasks as a Non-Intrusive Measure for Mode Awareness: A Simulator Study. Information, 11(5), 239. https://doi.org/10.3390/info11050239

457 458

Forster, Y., Hergeth, S., Naujoks, F., Beggiato, M., Krems, J. F., \& Keinath, A. (2019). Learning and Development of Mental Models during Interactions with Driving Automation: A Simulator Study. Proceedings of the 10th International Driving Symposium on Human Factors in Driver Assessment, Training and Vehicle Design: Driving Assessment 2019, 398-404. https://doi.org/10.17077/drivingassessment.1724

Gold, C., Körber, M., Hohenberger, C., Lechner, D., \& Bengler, K. (2015). Trust in Automation Before and After the Experience of Take-over Scenarios in a Highly Automated Vehicle. Procedia Manufacturing, 3, 3025-3032. https://doi.org/10.1016/j.promfg.2015.07.847

Hancock, P. A., Billings, D. R., Schaefer, K. E., Chen, J. Y. C., de Visser, E. J., \& Parasuraman, R. (2011). A Meta-Analysis of Factors Affecting Trust in Human-Robot Interaction. Human Factors, 53(5), 517-527. https://doi.org/10.1177/0018720811417254 
468

469

470

471

472

473

474

475

476

477

478

479

480

481

482

483

484

485

486

487

488

489

Hartwich, F., Beggiato, M., \& Krems, J. F. (2018). Driving comfort, enjoyment and acceptance of automated driving - effects of drivers’ age and driving style familiarity. Ergonomics, 61(8), 1017-1032. https://doi.org/10.1080/00140139.2018.1441448

Hartwich, F., Schmidt, C., Gräfing, D., \& Krems, J. F. (2020). In the Passenger Seat: Differences in the Perception of Human vs. Automated Vehicle Control and Resulting HMI Demands of Users. In H. Krömker (Ed.), HCI in Mobility, Transport, and Automotive Systems. Automated Driving and In-Vehicle Experience Design (Vol. 12212, pp. 31-45). Springer International Publishing. https://doi.org/10.1007/978-3-030-50523-3_3

Hartwich, F., Witzlack, C., Beggiato, M., \& Krems, J. F. (2018). The first impression counts - A combined driving simulator and test track study on the development of trust and acceptance of highly automated driving. Transportation Research Part F: Traffic Psychology and Behaviour. https://doi.org/10.1016/j.trf.2018.05.012

Helldin, T., Falkman, G., Riveiro, M., \& Davidsson, S. (2013). Presenting system uncertainty in automotive UIs for supporting trust calibration in autonomous driving. Proceedings of the 5th International Conference on Automotive User Interfaces and Interactive Vehicular Applications - AutomotiveUI '13, 210-217. https://doi.org/10.1145/2516540.2516554

Hergeth, S., Lorenz, L., \& Krems, J. F. (2017). Prior familiarization with takeover requests affects drivers' takeover performance and automation trust. Human Factors, 59(3), 457-470. https://doi.org/10.1177/0018720816678714

Hergeth, S., Lorenz, L., Krems, J., \& Toenert, L. (2015, June 22). Effects of Take-Over Requests and Cultural Background on Automation Trust in Highly Automated Driving. https://doi.org/10.17077/drivingassessment.1591 
Hergeth, S., Lorenz, L., \& Vilimek, R. (2016). Keep Your Scanners Peeled: Gaze Behavior as a Measure of Automation Trust During Highly Automated Driving. Human Factors, 3(58), 509-519. https://doi.org/10.1177/0018720815625744

Hoff, K. A., \& Bashir, M. (2015). Trust in automation: Integrating empirical evidence on factors that influence trust. Human Factors, 57(3), 407-434. https://doi.org/10.1177/0018720814547570

Khastgir, S., Birrell, S., Dhadyalla, G., \& Jennings, P. (2018). Calibrating trust through knowledge: Introducing the concept of informed safety for automation in vehicles. Transportation Research Part C: Emerging Technologies, 96, 290-303. https://doi.org/10.1016/j.trc.2018.07.001

Körber, M., Baseler, E., \& Bengler, K. (2018). Introduction matters: Manipulating trust in automation and reliance in automated driving. Applied Ergonomics, 66, 18-31. https://doi.org/10.1016/j.apergo.2017.07.006

Kraus, J., Forster, Y., Hergeth, S., \& Baumann, M. (2019). Two Routes to Trust Calibration: Effects of Reliability and Brand Information on Trust in Automation. International Journal of Mobile Human Computer Interaction, 11(3), 17.

Kraus, J., Scholz, D., \& Baumann, M. (2020). What's Driving Me? Exploration and Validation of a Hierarchical Personality Model for Trust in Automated Driving. Human Factors, 30. https://doi.org/10.1177/0018720820922653

Kraus, J., Scholz, D., Stiegemeier, D., \& Baumann, M. (2020). The More You Know: Trust Dynamics and Calibration in Highly Automated Driving and the Effects of Take-Overs, System Malfunction, and System Transparency. Human Factors: The Journal of the 
Human Factors and Ergonomics Society, 62(5), 718-736. https://doi.org/10.1177/0018720819853686

514 Lee, J. D., \& Moray, N. (1994). Trust, self-confidence, and operators’ adaptation to automation. International Journal of Human-Computer Studies, 40(1), 153-184. https://doi.org/10.1006/ijhc.1994.1007

Lee, J. D., \& See, K. (2004). Trust in Automation: Designing for Appropriate Reliance. Human Factors, 46(1), 50-80. https://doi.org/10.1518/hfes.46.1.50_30392

519 520

521 522

523

Lee, J., \& Moray, N. (1992). Trust, control strategies and allocation of function in human-machine systems. Ergonomics, 35(10), 1243-1270. https://doi.org/10.1080/00140139208967392

Manchon, J. B., Bueno, M., \& Navarro, J. (2020). From manual to automated driving: How does trust evolve? Theoretical Issues in Ergonomics Science, 1-27. https://doi.org/10.1080/1463922X.2020.1830450

Marsh, S., \& Dibben, M. R. (2003). The role of trust in information science and technology. Annual Review of Information Science and Technology, 37(1), 465-498. https://doi.org/10.1002/aris.1440370111

Mayer, A. K. (2008). The manipulation of user expectancies: Effects on reliance, compliance, and trust using an automated system. Georgia Institute of Technology.

Molnar, L. J., Ryan, L. H., Pradhan, A. K., Eby, D. W., St. Louis, R. M., \& Zakrajsek, J. S. (2018). Understanding trust and acceptance of automated vehicles: An exploratory simulator study of transfer of control between automated and manual driving. Transportation Research Part F: Traffic Psychology and Behaviour, 58, 319-328. https://doi.org/10.1016/j.trf.2018.06.004 
534 Moray, N., \& Inagaki, T. (1999). Laboratory studies of trust between humans and machines in 535 automated systems. Transactions of the Institute of Measurement and Control, 21(4-5), 203-211. https://doi.org/10.1177/014233129902100408

537

538

539

540

541

542

543

544

545

546

547

548

549

550

551

552

553

554

Morris, D. M., Erno, J. M., \& Pilcher, J. J. (2017). Electrodermal Response and Automation Trust during Simulated Self-Driving Car Use. Proceedings of the Human Factors and Ergonomics Society Annual Meeting, 61(1), 1759-1762. https://doi.org/10.1177/1541931213601921

National Highway Traffic Safety Administration, , Department of Transportation. (2017). INCLAPE16-007. https://static.nhtsa.gov/odi/inv/2016/INCLA-PE16007-7876.PDF

Navarro, J. (2019). A state of science on highly automated driving. Theoretical Issues in Ergonomics Science, 20(3), 366-396. https://doi.org/10.1080/1463922X.2018.1439544

Navarro, J., François, M., \& Mars, F. (2016). Obstacle avoidance under automated steering: Impact on driving and gaze behaviours. Transportation Research Part F: Traffic Psychology and Behaviour, 43, 315-324. https://doi.org/10.1016/j.trf.2016.09.007

Navarro, J., Osiurak, F., Ovigue, M., Charrier, L., \& Reynaud, E. (2019). Highly Automated Driving Impact on Drivers' Gaze Behaviors during a Car-Following Task. International Journal of Human-Computer Interaction, $1-10$. https://doi.org/10.1080/10447318.2018.1561788

Navarro, J., Reynaud, E., \& Gabaude, C. (2017). Eye movement analysis in dynamic scenes: Presentation and application of different methods in bend taking during car driving. Le Travail Humain, 80(3), 307. https://doi.org/10.3917/th.803.0307 
555 Parasuraman, R., \& Riley, V. (1997). Humans and Automation: Use, Misuse, Disuse, Abuse. Human Factors, 39(2), 230-253. https://doi.org/10.1518/001872097778543886

Payre, W., Cestac, J., Dang, N.-T., Vienne, F., \& Delhomme, P. (2017). Impact of training and invehicle task performance on manual control recovery in an automated car. Transportation Research Part F: Traffic Psychology and Behaviour, 46, 216-227. https://doi.org/10.1016/j.trf.2017.02.001

Payre, W., Cestac, J., \& Delhomme, P. (2016). Fully Automated Driving: Impact of Trust and Practice on Manual Control Recovery. Human Factors, 58(2), 229-241.

SAE International. (2016). Taxonomy and Definitions for Terms Related to Driving Automation https://doi.org/10.1177/0018720815612319 Systems for On-Road Motor Vehicles. https://doi.org/10.4271/J3016_201609

Sauer, J., Chavaillaz, A., \& Wastell, D. (2015). Experience of automation failures in training: Effects on trust, automation bias, complacency and performance. Ergonomics, 59(6), 767780. https://doi.org/10.1080/00140139.2015.1094577

569 Schaefer, K. E., Chen, J. Y. C., Szalma, J. L., \& Hancock, P. A. (2016). A Meta-Analysis of Factors Influencing the Development of Trust in Automation: Implications for Understanding Autonomy in Future Systems. Human Factors, 58(3), 377-400. https://doi.org/10.1177/0018720816634228

Schmidt, C., Hartwich, F., \& Krems, J. F. (2021). Looking at Driving Automation from a Passenger’s Perspective: Driving Experience and Gaze Behavior During Fully Automated vs. Human Vehicle Control. In T. Ahram, R. Taiar, K. Langlois, \& A. Choplin (Eds.), 
Human Interaction, Emerging Technologies and Future Applications III (Vol. 1253, pp. 39). Springer International Publishing. https://doi.org/10.1007/978-3-030-55307-4_1

578

579

580

581

582

583

584

585

586

Schwarz, C., Gaspar, J., \& Brown, T. (2019). The effect of reliability on drivers’ trust and behavior in conditional automation. Cognition, Technology \& Work, 21(1), 41-54. https://doi.org/10.1007/s10111-018-0522-y

Seppelt, B. D., \& Lee, J. D. (2019). Keeping the driver in the loop: Dynamic feedback to support appropriate use of imperfect vehicle control automation. International Journal of HumanComputer Studies, 125, 66-80. https://doi.org/10.1016/j.ijhcs.2018.12.009

Strauch, C., Mühl, K., Patro, K., Grabmaier, C., Reithinger, S., Baumann, M., \& Huckauf, A. (2019). Real autonomous driving from a passenger's perspective: Two experimental investigations using gaze behaviour and trust ratings in field and simulator. 14.

Walker, F., Wang, J., Martens, M. H., \& Verwey, W. B. (2019). Gaze behaviour and electrodermal activity: Objective measures of drivers' trust in automated vehicles. Transportation Research Part F: Traffic Psychology and Behaviour, 64, 401-412. https://doi.org/10.1016/j.trf.2019.05.021

Wintersberger, P., Frison, A.-K., Riener, A., \& Boyle, L. N. (2016). Towards a Personalized Trust Model for Highly Automated Driving. Proceeding of M\&C, 4, 8.

Wintersberger, P., \& Riener, A. (2016). Trust in Technology as a Safety Aspect in Highly Automated Driving. I-Com, 15(3). https://doi.org/10.1515/icom-2016-0034

Yusof, N. Md., Karjanto, J., Terken, J., Delbressine, F., Hassan, M. Z., \& Rauterberg, M. (2016). The Exploration of Autonomous Vehicle Driving Styles: Preferred Longitudinal, Lateral, and Vertical Accelerations. Proceedings of the 8th International Conference on Automotive 
User Interfaces and Interactive Vehicular Applications - Automotive’UI 16, 245-252. https://doi.org/10.1145/3003715.3005455

600 Zhang, T., Tao, D., Qu, X., Zhang, X., Lin, R., \& Zhang, W. (2019). The roles of initial trust and 601 perceived risk in public’s acceptance of automated vehicles. Transportation Research Part 602 C: Emerging Technologies, 98, 207-220. https://doi.org/10.1016/j.trc.2018.11.018

603 